\title{
Problems of organization and search the knowledge base in the CRM-systems
}

\author{
Ostroukh Andrey Vladimirovich ${ }^{1}$, Belousova Angelina Igorevna ${ }^{2}$, \\ Pavlov Dmitriy Alekseevich ${ }^{3}$, Yurchik Petr Francevich ${ }^{4}$ \\ ${ }^{I}$ Russian Federation, full member RAE, Doctor of Technical Sciences, Professor, Department of «Automated \\ Control Systems». Moscow Automobile \& Road construction State Technical University, ostroukh@mail.ru \\ ${ }^{2}$ Russian Federation, Undergraduate Student, Department of «Automated Control Systems». Moscow \\ Automobile \& Road construction State Technical University, angy90@inbox.ru \\ ${ }^{3}$ Russian Federation, Ph. D., Associate Professor, Department of «Automated Control Systems». Moscow \\ Automobile \& Road construction State Technical University, Dmitriy.pavlov@it-sys.ru \\ ${ }^{4}$ Russian Federation, Doctor of Technical Sciences, Professor, Department of «Automated Control Systems». \\ Moscow Automobile \& Road construction State Technical University, upf.madi@mail.ru
}

\begin{abstract}
The main aims of work is to study the problems of the knowledge organization in the field of information technology. Problems of the organization of knowledge and analysis of the process of the search for them in the «Customer Support» are considered in this article. Work also aimed to show the importance of knowledge organization in the enterprise. An approach to the development of intelligent system handling of knowledge, which will reduce the time of finding relevant information, will increase the accuracy of the information, provide the ability to analyze the information at different levels of decision-making, ensure efficiency and accessibility of information.
\end{abstract}

Keywords: - management, modeling, information environment, automated control systems, decision support, information technology, business processes, Customer Relationship Management (CRM).

\section{INTRODUCTION}

Dynamics of the modern business environment forces companies to look for new ways of strengthening their competitive advantages. For many of them tightening of the competition in the markets, on which they depend, from the area of external action all more definitely is turning into major domestic problems. Increased competition in the markets on which they depend, from the field of external influence more and more definitely turning into a major internal problems for many of them $[1-20]$. Therefore there is a need for more effective management of information, a need of introduction of CRM.

Quality customer service - the most significant factor in the success of every enterprise services. High level of service increases the number of loyal customers, creates a favorable image of the company, which in turn leads to growth its financial performance. In this regard, CRM application is actual, is aimed at building a sustainable business concept and business strategy, the core of which is a "customer-centric" approach. This raises an actual research problem in the systems development of corporate sites and approaches to creation of information systems on the basis of CRM.

Support systems are directed to increase the efficiency of companies using the application software. They allow to take specifics of each company into consideration. Individual approach to the organization of the company plays a major role. If companies are using support system, that they have a purpose, for example, improving employee performance or improving its profitability and etc. [1]. All companies during of its activity are accumulating multitude knowledge: experience, information, ideas, relations. If you can correctly manage knowledge, which occur during the theoretical and practical activities of staff, it allows to achieve the goal, that sets the company [2].

\section{THE DEVELOPMENT EVOLUTION OF DECISION SUPPORT SYSTEMS}

Decision support systems have developed rapidly and have been following path: from transaction processing systems to expert systems. The integration of the computer information systems is given on a Figure 1 and in a table $1[8,9]$. 


\section{Expert Systems ES 1980}

Data Design Systems DDS 1980

Open-Architecture-Systems OAS

Management Information Systems MIS 1960

Transaction processing systems TSP 1950

Figure 1. The development of management information systems and decision support systems

The expert system is considered the top of information systems, also is a kind of systems of support DDS, which is designed to meet the goal, set by leadership.

Customer support system which developed at JSP "Information Technology" - it is expert system, whose purpose was to speed up the process of working with requests.

Table 1. Comparative analysis of expert systems and decision support systems DDS

\begin{tabular}{|l|l|l|}
\hline Target & $\begin{array}{l}\text { Assistance to a person in } \\
\text { making a decision }\end{array}$ & Simulating experts activity. \\
\hline Who makes the decision? & $\begin{array}{l}\text { Decision maker and (or) } \\
\text { system }\end{array}$ & System \\
\hline Main orientation & Decision making & $\begin{array}{l}\text { Transfer of expertise (expert-computer - } \\
\text { man), replicating expertise }\end{array}$ \\
\hline Who mainly asks questions? & Decision maker & PC \\
\hline Support object & Person, group, or organization & Persons and groups \\
\hline $\begin{array}{l}\text { From what information mainly } \\
\text { manipulated? }\end{array}$ & Numeric & Symbolic \\
\hline Characteristics of the problem area & $\begin{array}{l}\text { Comprehensive, } \\
\text { complex }\end{array}$ & broad, \\
\hline Type of task & Random, unique & Repetitive \\
\hline Contents of the database & The actual values & Procedural and factual knowledge \\
\hline $\begin{array}{l}\text { Ability to carry out logical } \\
\text { reasoning }\end{array}$ & No & Yes, limited \\
\hline Ability to obtain an explanation & Limited & Yes \\
\hline
\end{tabular}

\section{TRADITIONAL MARKETING AND CRM- APPROACHES TO BUILDING} INTEGRATED IT-SOLUTIONS

According to the data of one organization engaged in research innovation of business - processes, the average investment in CRM companies (operating in the U.S. and European markets) was approximately \$ 3 million. $69 \%$ of respondents argue that the amount of their investments did not exceed 5 million USD, and more than $13 \%$ invested 10 million or more.

Table 2. Comparison of traditional marketing and CRM-integrated approaches and IT-solutions

\begin{tabular}{|l|l|l|l|l|}
\hline Concept & Identification & Differentiation & Interaction & Customization \\
\hline Task & Client Identification & $\begin{array}{l}\text { Assessment of the } \\
\text { client and his needs }\end{array}$ & $\begin{array}{l}\text { Create long-term } \\
\text { relationships }\end{array}$ & $\begin{array}{l}\text { Implementation of } \\
\text { the client's needs }\end{array}$ \\
\hline $\begin{array}{l}\text { Traditional } \\
\text { Marketing }\end{array}$ & Impracticability & Cluster differentiation & Call-centre & Sales / services \\
\hline CRM & $\begin{array}{l}\text { Profiling the } \\
\text { customer's identity }\end{array}$ & $\begin{array}{l}\text { Analysis of the } \\
\text { personal level }\end{array}$ & $\begin{array}{l}\text { Automated } \\
\text { Call-center }\end{array}$ & $\begin{array}{l}\text { Sales and Marketing } \\
\text { Automation }\end{array}$ \\
\hline $\begin{array}{l}\text { Technological } \\
\text { solutions }\end{array}$ & $\begin{array}{l}\text { Cookies and } \\
\text { personalization } \\
\text { Web-client profile }\end{array}$ & $\begin{array}{l}\text { Information passing } \\
\text { and analytics }\end{array}$ & $\begin{array}{l}\text { Internet } \\
\text { applications and } \\
\text { WAP-telephony }\end{array}$ & $\begin{array}{l}\text { ERP and emmerce } \\
\text { comm }\end{array}$ \\
\hline
\end{tabular}


Those who have an understanding of the implementation of ERP systems in your company, will be able to evaluate the cost of implementing CRM is very simple - should only increase the cost of ERP implementation twice.Terms of introduction of ERP of system average takes for 2 years, and expenses on system support within these two years fluctuate within $0,4 \%-1,0 \%$ of a revenue of the company.

\section{SYSTEM «CUSTOMER SUPPORT»}

System «customer support» it's a real system developed on object-oriented programming language $1 \mathrm{C}$ and currently it is in use (Figure 2).

Main questions, that stood before developers, when they are elaborated the system:

1. Receiving and recording all customer requests, both by phone and e -mail, or through self-registration request at the web-site.

2. Search for information in completed requests for faster searching solutions to new.

3. Attaching files to the request for explain the situation.

4. Tracking request execution - who, when and what was doing with the request and its current implementation.

5. Fixing time working with the request.

6. Creating support levels - Reception request $\rightarrow$ Transfer it to the first level (if the problem is not solved at the receiving step) $\rightarrow$ Transfer to the second level , if the problem cannot be solved at the first level

7. Possible to redirect requests among employees.

8. User notification about the decision of him request.

9. Fixing state and the number of database (degree attunement).

10. Fixing the last set of releases.

11. Storing information in a database for remote access to the client.

12. Storage and support up to date information about the settings in the databases, including the configuration files and external reports.

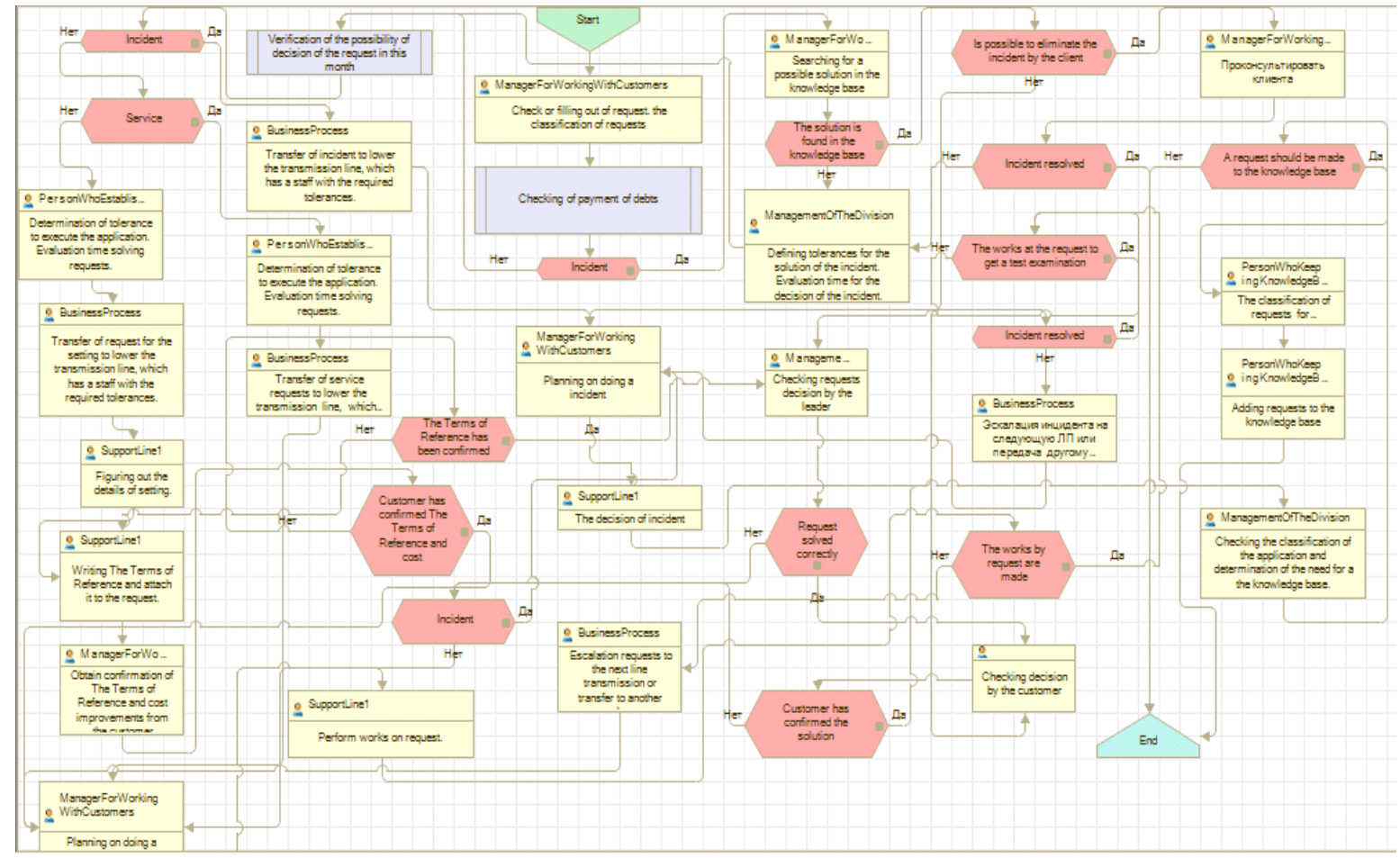

Figure 2. The route map of the business - process "Request for service 1C"

1 support line - it is generalists. 2 support line - it is specialist narrow profile, who receive incidents from the first line specialists, if them can't solve it at the previous level. At the basis of this system located a multi-level principle that allows you to not distract more skilled specialists at solving problems that can solve less qualified specialists and to ensure uniform load for the less skilled specialists.

This principle has a drawback - it is increased the time to solve the problem, for example, if the problem has been sorted out by support specialist of the first line, who first encountered it, which significantly increases the time of its decision. When it is impossible to solve, the problem escalated to a more qualified specialist. 
To resolve that drawback is necessary, in the absence of solutions in the knowledge base, to choose the level of support depending on the complexity of the problem or a particular specialist, who had previously dealt with a similar problem, which will speed up the process of working with applications.

Decision support system for selecting the desired support line and support specialist should be based on the data from knowledge base, but does not produce a direct search by the classification of incidents or coincidentally words and search for similar incidents. Based on the analysis about what support line used to solve these incidents and what employee make recommendations to the operator for a final decision.

To organize the search in the knowledge base is proposed to operate the method of cluster analysis and artificial neural network, at first it's necessary to carry out a rough selection of similar incidents with neural network, and then, using a larger number of factors affecting the selection, produce clusters.

The main problem, which stood before developers - it is automation of work with clients. Important process in this work is the process of making his application and its solution. Business processes for customer service applications are established in this system, but need to consider the process of organizing knowledge for them.

As a result, we obtain a system that stores information about all applications and searches for similar applications in the knowledge base, which greatly accelerates the process of closing applications. In many cases, the manager manages to solve the problem and advise the client on the phone, as many incidents can solve the first line of support staff, while not referring to the second line support.

\section{KNOWLEDGE REPRESENTATION FOR INTELLIGENT SYSTEMS}

The techniques used most frequently to represent the expert knowledge are [7 - 10]:

- frames;

- predicate calculus;

- production systems;

- semantics nets;

- fuzzy logic.

As a system of knowledge representation, I chose a production system. By products we understand an expression:

If $\langle X 1, X 2 \ldots X n>$ then

$<\{Y 1, D 1\}, \ldots\{Y m, D m\}\rangle$,

where: Xi,Yi - logical expressions, Di - reliability factor $(0,1)$ or confidence factor $(0,100)$. [5]

Production systems is a set of rules that apply as a knowledge base, also called the rule base. Knowledge can be represented as a series of IF-THEN rules where the first part or the antecedent of the rule is called the premise, and the second part or the consequence is termed the conclusion. When a premise is judged to be true, the rule is "triggered," and its conclusion becomes a fact known to the rest of the production system. [3]

A. Nyuell and G. Saymon noted in GPS (Global Position System), what products similar with problemsolving skills in human long-term memory and when system operationg output data is not change like skills in long-term memory [7 - 9]. To solve the problem, they called on the "sample." Working memory of the production system similar to the short-term human memory. Workspace content after solving the problem is not saved [4].

Work of the product system initiates the initial description of the problem. Further, from the production set of rules are selected, only those rules there are suitable for further use. These rules created as conflicting set, for the selection of this rules from the conflicting sets uses different strategies, which may be simple or complex.

Production model has no mechanism to exit the unsolvable states in the search process. It works as long as there are no more products what available. In practice, the implementation of production systems contains mechanisms to return previous state for control the search algorithm $[5,9]$.

\section{SEARCH THE KNOWLEDGE BASE}

Find similar solutions to the application may be made either by specific sections or the entire knowledge base. In order to organize the automatic storage of information used stemming, finding words for the root word.

On the general scheme of the search direction of the incident escalation (Figure 3, [6]) shows the sequence of the search line and support personnel who can most qualified and quickly resolve an incident that can't be solved on the first line of support by a simple query to the knowledge base. 


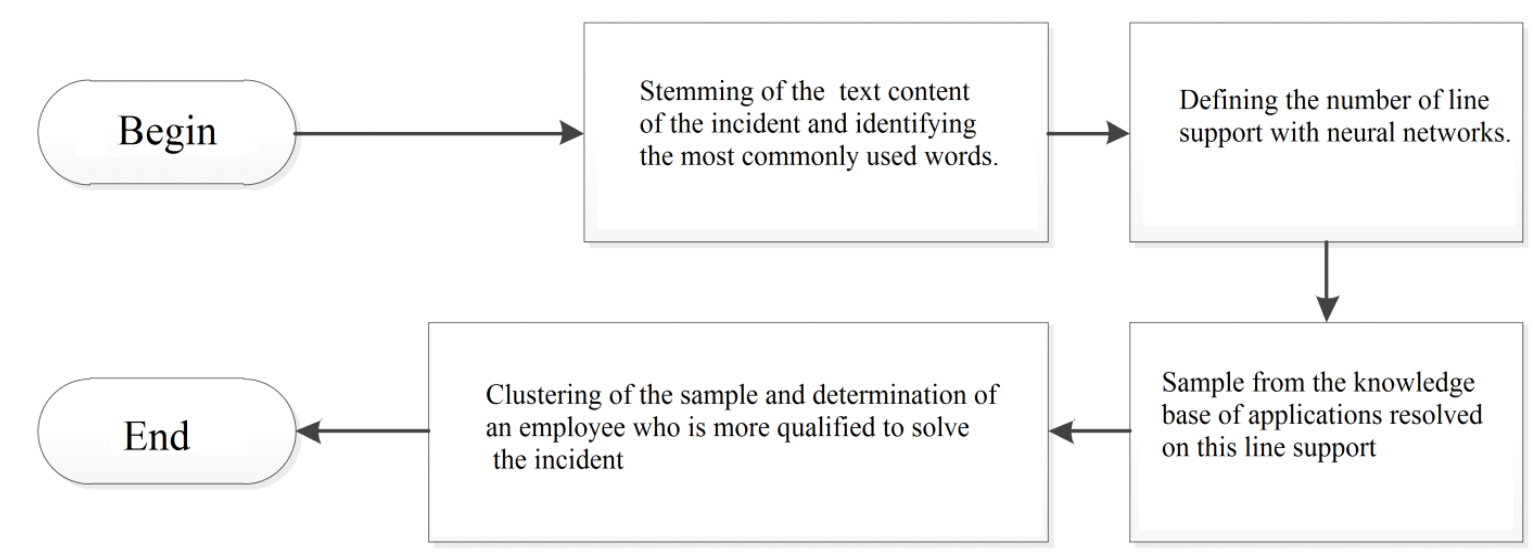

Figure 3. The general scheme of the search direction of the incident escalation

\section{CONCLUSION}

Using of the knowledge and using of the management has many advantages. In this paper we analyzed what is a support system, what is a knowledge management, customer support system has been considered, what is a search the knowledge base. Creating such an intellectual system handling knowledge will reduce the time to find specific information, increase the reliability of the information, provide the ability to analyze information at different levels of decision-making, ensure efficiency and accessibility of information ( access to the system from the Internet ).

\section{REFERENCES}

[1] Belousova A.I., Ostroukh A. V., Krasnyansky M.N., Varlamov O. O. Formation of multi-level model of multi-agent system using mivar. Prospects of science. 2011. No 5(20). pp. 57 - 61.

[2] Pavlov D.A. Decision support system for improving the allocative efficiency of applications between employees and for reducing the time required to resolve incidents in the systems service desk. - Moscow. 2011. pp. 4-7.

[3] Pospelov D.A. About the "human" reasoning in intelligent systems. The logic and its simulation. The Scientific Council on the Complex Problem "Cybernetics" of the Presidium of the USSR Academy.Moscow, 1983. pp. 5-37.

[4] P. Winston Artificial intelligence. - M.: Mir, 1980. - 519 p.

[5] Ostroukh A.V., Solntcev A.A., Soldatov N.V., Novitsky K.A., Yakunin P.S., Initial period of the simulation study on the accuracy of the average integral evaluation of simulation models. Vestnik MADI. 2010. Issue 2(21). pp. 61-65.

[6] Ostroukh A.V., Tian Yuan. Modern methods and approaches to building management systems of production and technological activities of industrial enterprises. Automation and Control in Technical Systems. 2013. No 1(3). pp. 29-31.

[7] Ostroukh A.V., Tian Yuan. Development of information-analytical system process monitoring automotive industry. In the World of Scientific Discoveries. 2013. No 8.2 (44). pp. 191-205.

[8] Surkova N.E., Ostroukh A.V. Methods of designing information systems. Moscow: RosNOU, 2004.144 p. ISBN 5-89789-021-8.

[9] Ostroukh A.V., Chernov E.A., Nguyen Duc Thanh. Automation of production management. Improving the efficiency of automated analytical systems to the automotive industry. Saarbrucken, Germany: LAP LAMBERT Academic Publishing, 2013. 285 p. - ISBN 978-3-659-34762-7.

[10] Ostroukh A.V., Tian Yuan. Integration of system components monitoring. Young Scientist. 2013. No 10. pp. 182-185.

[11] Nikolaev A.B., Ostroukh A.V. Information technology in management and transport logistics: a tutorial. Saint-Louis, MO, USA: Publishing House Science and Innovation Center, 2013. 254 p. ISBN 978-0-61567110-9.

[12] Tian Yuan, Ostroukh A.V. Monitoring environment condition of Chinese industrial enterprises. European journal of natural history. 2013. No 5. pp. 34-35.

[13] Ostroukh A.V., Krasnyansky M.N., Davydova T.L., Varlamov O.O. Analysis of possibilities of using mivar technology in systems of artificial intellect and modern robotics. Transactions TSTU. 2011. Vol.17. No 3. pp. 687-694.

[14] Ostroukh A.V., Sandu R.A., Varlamov O. O. Mivar automated control systems of technological processes for oil industry of Russia. Automation, telemechanization and communication in the oil industry. 2011. No 11. pp. 37-41. 
[15] Ostroukh A.V. Bases of construction of artificial intelligence systems for industrial and construction enterprises. Moscow: «TechPoligraphCenter», 2008. 280 p. ISBN 978-5-94385-033-2.

[16] Ostroukh A.V. Information technology in scientific and industrial activity / [Ed. A.V. Ostroukh] Moscow: «TechPoligraphCenter», 2011. 240 p. ISBN 978-5-94385-056-1.

[17] Ostroukh A.V., Nikolaev A.B. Development of virtual laboratory experiments in iLabs. International Journal of Online Engineering (IJOE). 2013. Vol. 9, No 6. pp. 41-44. DOI: 10.3991/ijoe.v9i6.3176.

[18] Ostroukh A.V., Barinov K.A., Nikolaev A.B., Stroganov V.Yu. Interactive Game Modeling Concept for Personnel Training at the Industrial Enterprises. World Applied Sciences Journal (WASJ). 2013. Vol. 28, No 1. pp. 44-55. DOI: 10.5829/idosi.wasj.2013.28.01.1876.

[19] Ostroukh A.V., Nikolaev A.B. Development of virtual laboratory experiments in iLabs. International Journal of Online Engineering (IJOE). 2013. Vol. 9, No 6. pp. 41-44. DOI: 10.3991/ijoe.v9i6.3176.

[20] Ismoilov M.I., Nikolaev A.B., Ostroukh A.V. Training and retraining of personnel and industrial enterprises of transport complexes using mobile technology. Saint-Louis, MO, USA: Publishing House Science and Innovation Center, 2013. 166 p. ISBN 978-0-615-67111-6.. 